\title{
The Effects of Various Stimuli on Motivation and Physical Fitness of Physically Active and Non-Active Students
}

\author{
Martin Pacholek (iD * \\ Department of Physical Education, King Fahd University of Petroleum \& Minerals, Kingdom of Saudi \\ Arabia.
}

Submitted 25 November 2020; Accepted in final form 31 January 2021.

\begin{abstract}
Background. Execution of fitness testing in physical education classes is influenced by students' motivation. Therefore, addressing new testing approaches seems necessary to more accurately measure student performance. Objectives. This study presents changes in fitness performance after applying a physical fitness tests battery (without external stimuli - WS) and with external stimuli (verbal encouragement - VE, performance feedback and goal-oriented) for university students. Methods. The participants (432, BMI $24.72 \pm 5.97$, age $19.1 \pm 2.1$ ) were divided into non-physically active (NAS) and physically active students (PAS). They underwent a battery of fitness tests with and WS. Results. The results showed that NAS improved power in bench press $(21.3 \mathrm{~W}, 5.15 \%, \mathrm{P}=0.021)$ after performance feedback compared to attempts (WS). In $10 \mathrm{~m}$ sprint, PAS decreased the time after a combination of VE and goal-oriented stimuli (COM) compared to WS $(0.029 \mathrm{~s}$, $1.5 \%, \mathrm{P}=0.000)$ and in the $30 \mathrm{~m}$ sprint $(0.079 \mathrm{~s}, 1.65 \%, \mathrm{P}=0.006)$ and after COM compared to VE in the $10 \mathrm{~m}$ sprint test $(0.024 \mathrm{~s}, 1.24 \%, \mathrm{P}=0.001)$ and in the $30 \mathrm{~m}$ sprint $(0,089 \mathrm{~s}, 1.86 \%, \mathrm{P}=0.000)$. NAS decreased the time after COM compared to VE in the $30 \mathrm{~m}$ sprint test $(0.053 \mathrm{~s}, 1.06 \%, \mathrm{P}=0.006)$. NAS and PAS also improved in height after VE compared to WS in the height jump test $(1.53 \mathrm{~cm}, 6.39 \%, \mathrm{P}=0.000$ resp. $1.24 \mathrm{~cm}, 4.85 \%, \mathrm{P}=0.000)$, after COM compared to WS $(2.11 \mathrm{~cm}$, $8.81 \%, \mathrm{P}=0.000$ resp. $1.83 \mathrm{~cm}, 7.16 \%, \mathrm{P}=0.000)$ and after $\mathrm{COM}$ compared to $\mathrm{VE}(0.58 \mathrm{~cm}, 2.28 \%, \mathrm{P}=0.013$ and $0.59 \mathrm{~cm}$, $2.2 \%, \mathrm{P}=0.002)$. Conclusion. These findings indicate that giving external stimuli is more effective for testing explosive strength, acceleration, and speed than WS and that PAS achieved better improvements in fitness tests after applying COM and NAS improved mainly after just one external stimulus.
\end{abstract}

KEYWORDS: Physical Education, Verbal Encouragement, External Stimuli, Motivation, Feedback.

\section{INTRODUCTION}

Many researchers in the field of Physical Education (PE) look for the best methods and resources to motivate students to achieve their best results. Many of them publish different topics about the importance of motivation in PE and how to motivate students to achieve higher performance and better results. PE teachers have a limited amount of time with students during the week and for this reason they have to be very purposeful in using appropriate teaching and learning methods during class time with an aim to enhance student motivation and performance.
Motivation is the reason for people's actions, desires, and needs (1). Egli et al. (2) obtained data that male students are more motivated by a need for power, competition and challenge and for these reasons we should try to build this kind of environment during the class. The findings also suggest that if the goal of teaching is to increase enjoyment, ability, and effort of students to pursue their fitness goals, then teachers must consider the types of communicative messages that students are motivated by and respond to positively (3).

*. Corresponding Author:

Martin Pacholek, Ph.D.

E-mail: mpacholek@post.cz 
Motivation greatly influences an individual's performance in situations where one is physically capable of performing the task but is uncertain about his capabilities. In general terms, motivation refers to the intensity and direction of behavior (4). Part of the physical education classes is physical fitness testing. Goudas (5) concluded that reactions to fitness testing depending on a student's personal goal profile, performance, and perceived success. It can cause student embarrassment and anxiety but some strategies can be developed that can provide students with positive feedback, encourage students to set fitness goals and thus motivate students to exert maximal effort and achieve maximal results (6).

Motivation climate, or positive social environment may influence and modulate motivation of individuals involved in sports. Experience has shown that conventional encouragement and feedback during the test may affect its outcome (7). One strategy to motivate students is to add some external stimuli during execution of fitness tests, which can improve student motivation to achieve maximum performance. Movement itself is a pattern of responses to recognized stimuli. The stimuli (perceived) may be visual, kinesthetic, auditory or other sense stimuli, or a combination of the stimuli of several senses (8). Applied behavior analysis has begun to emphasize the importance of stimuli in controlling human behavior (9). The importance of external stimuli on people's feelings shows study (10), where college students increase overall enjoyment and mood during exercise after using external stimuli (audiovisual) compared to exercising without stimuli during treadmill walking. Argus et al. (11) stated that psychological interventions may have greater potential to affect performance in untrained or novice athletes.

Within the realm of physical activity settings, a growing body of research has provided evidence for the influential role of positive feedback on perceptions of competence and intrinsic motivation (12, 13). Badami et al. (14) distinguished two different types of feedback used while teaching and coaching: intrinsic feedback (response-produced feedback that is available to learners from their sensory system both during and as a consequence of the performance) and augmented feedback (information received from an external source that supplements the learner's own sensory information, intrinsic feedback). These two types of feedback, when used together, help students and athletes thrive and improve their performance (15). Moreover, the type of feedback provided during or between a series of tests can affect results (16). The feedback teachers and coaches provide to students and athletes influence their achievement in physical education and sports settings. Practitioners can use feedback when teaching proper movements or skills or as a motivation tool and it allows students and athletes to get information about their performance or increase their motivation. Feedback can be used to correct mistakes and affect one's motivation levels. Feedback used while teaching and coaching may be delivered verbally, visually, or through written form, and does not always need to be highly detailed in order to improve student and athlete motivation $(17,18)$. The link between feedback received from PE teachers and students' perceived competence has been confirmed also in correlational studies. Koka and Hein (19) found that perceived positive teacher feedback predicted students' perceptions of competence and intrinsic motivation.

The other simple motivation stimulus which could be used during physical education classes is verbal encouragement (VE). It is generally accepted that VE can increase students academic performance (20). It is also very often used to motivate athletes to keep or increase effort during exercise or testing (16) and is recommended in several exercise testing guidelines (21-23) as positive stimuli for performance, physiological responses, enjoyment and positive mood (24). The positive effect of verbal encouragement was mostly recorded during endurance tests on athletes $(24,25)$ and students $(26,27)$ in maximal oxygen uptake, distances covered and final heart rate. In studies $(28,29)$ VE lead to increase in force production and electromyographic activation during exercise. In another study Lee (30) stated, that VE seems to be effective in maintaining central activation during the strength exercise. Further study confirmed these positive effects in strength performance regarding encouragement volume and word choice (31).

Challenging situation with specific goal is another factor in motivation, which could enhance performance. Verheijen (32) stated that football players, which executed $10 \mathrm{~m}$ sprints in football situation compared to one or two players 
sprinting in isolation achieved significantly better results. Further study (33) showed that reaction time is better when the Agility Test is performed in simulated competitive than noncompetitive conditions or that runners cover longer distances during VO2max test in competitive conditions (34).

Only a very limited number of studies has investigated the influence of these external stimuli on performance during maximal exercise testing (25) and most of them just on effect of verbal encouragement in endurance or strength exercises. Moreover, this study investigated their effects on 432 physically active and non-active students. Therefore, the purposes of this paper are to discuss the importance of using goal-oriented feedback and verbal encouragement as the stimuli with active and non-active students to help motivate them to a higher level of performance and to show how practitioners may use these stimuli to better influence student's motivation and results during physical education classes. This project aims to determine different and more affective variables (feedback, verbal encouragement, goal-oriented stimuli settings) and examine affective responses to exercise behavior as a predictor of motivation for achieving greater results and performance during fitness testing on explosive strength and speed abilities. It was hypothesized that using selected external stimuli (performance feedback, verbal encouragement and goal-oriented stimuli) will have a greater impact than not using external stimuli on students' (PAS and NAS) fitness performance. Furthermore, a combination of external stimuli (verbal + non-verbal) will have a greater impact on PAS and NAS fitness performance than if only one external stimulus were used.

The innovative aspect of this study is that the fitness testing with different stimuli is done on a homogenous groups of STEAM University students (physically active and non-active). Physical education is not primary subject for students from STEAM University and, for this reason, it is much more difficult for lectures to motivate students to be physical active and exert maximal effort during physical fitness tests. Verbal encouragement from the teacher or other external stimuli can lead to different responses from active and non-active students compared to simple execution of exercise without any external stimuli. The type and nature of the exercise could be the second factor in determining when certain external stimuli are more effective, ineffective or counterproductive. The results of the study can help physical education teachers understand the effectiveness of selected stimuli in motivating physically active and non-active STEAM students to achieve better results in selected fitness tests.

\section{MATERIALS AND METHODS}

Participants. The study was a double blind group - time parallel experimental research with the dependent physical ability variables. The independent variables were the stimuli in all of the fitness tests. Participants of this research were 432 male students from King Fahd University of Petroleum \& Minerals (KFUPM) who fully completed all measuring activities. Based on the formal standardized questionnaire students were divided into two groups (after the testing): physically active students and non-active students. PAS stated in the questionnaire that they are physically active at least three or more times per week minimum for 30 minutes over the last 5 years. A total of 254 PAS with average body mass index (BMI) $24.9 \pm 5.57$ and calendar age 19.2 \pm 0.9 were recorded. In the NAS group, there were 178 students (BMI 24.5, age $19.0 \pm 1.1$ ).

Selection Criteria. The participants were chosen by convenience sampling. All of them were being a member of the university, age range between 18 and 20 years. The medical history was taken to deselect unhealthy, injured or students with mental diseases from the testing.

Data Collection. Data was obtained by questionnaire and measurement-testing methods. At the beginning of the study each student had to fill out a questionnaire. The questionnaire was supposed to get basic demographic information about students: their name, age, body mass index and information how many times they were on average physically active at least 30 min per week in the last five years. If the amount of average physical activity per week was 3 and higher, then the students were classified as physically active students but if the amount of physical activity was two times or less, then they were classified as non-physically active students.

Three different fitness tests (FT) were chosen based on different physical abilities (explosive strength upper and lower body, speed and acceleration). Factors considered were their measure, their practicality, complexity and maximum intensity and concentration required 
for their execution. The tests were selected from published literature $(35,36)$ and were considered commonly used in sport.

- Bench press

- 10 and $30 \mathrm{~m}$ sprint test

- High jump with FiTRO JUMPER

Testing Procedure. All students were asked to not be physically active 48 hours before testing and were informed about the procedure and main purpose of each test. Students were told about all tests, their variations and physical abilities, which they measure before the measurement but they were not informed about the specific aims or hypotheses of the study until end of the project. They were instructed to put their maximal effort in each repetition. They underwent four weeks of measurement of their physical abilities under different stimuli in counterbalancing conditions. All testing procedures were done by the same examiner (principal investigator) for better reliability of results and for same volume and frequency of verbal encouragement or feedback during testing. Students were advised not to eat at least 3 hours and not to exercise at least 2 days before the testing. These FT were applied with and without external stimuli. All students had three attempts at each FT. The first attempt was without the external stimuli and the second and the third were with additional external stimuli. The order of execution of FT with external stimuli was regularly changed (counterbalancing) during the measurement but cases of FT without stimuli way of testing were always the student's first attempt. The testing was always in the same time for each participant in the morning hours and each student got same instructions regarding how to perform the tests. The procedures followed were in accordance with the ethical standards on human experimentation stated in compliance with the 1964 Helsinki Declaration and its later amendments.

The following three kind of stimuli were applied:

- No external stimulus applied

- Verbal encouragement (VE) or verbal feedback about their previous performance

- Based on a combination of reaching a certain goal-oriented aim together with verbal encouragement or VE with verbal feedback about their performance

Each student completed five days of measurements in three weeks. The testing of one ability was measured within two days and there were four days off (Wednesday - Monday) between the testing of one ability. Only the testing of lower body explosiveness was done in one day.

The FT was in this order:

1. Explosive strength of upper body (Bench press)

2. Acceleration and speed (10 and $30 \mathrm{~m}$ sprints)

3. Explosive strength of lower body (High jump)

Characteristics and of selected tests:

Bench - press. The bench press is a common exercise for developing upper body strength.

On the first day of measurement students warmed up with ten push-ups and 4-6 repetitions with an empty barbell $(16-20 \mathrm{~kg})$. The instructor observed and corrected the proper execution of this exercise during warm up with each student and then the diagnostic series for assessing onerepetition maximum (1RM) followed. Based on the results $55-65 \%$ from $1 \mathrm{RM}$ was calculated for each student. On the second day of testing, students used the same warm-up as on the first day plus one repetition of their calculated weight with maximum acceleration in concentric phase. Then the testing (with their 55-65\% from 1RM) of maximal power (W) was applied. Thereafter, participants were familiarized with the test procedures. Each student had three attempts with one repetition. The rest between each repetition was $20-30$ s. Their task was to produce maximum acceleration during the concentric phase in each repetition on the different stimuli.

The selected stimuli were:

1. Students performed the exercise without external stimuli.

2. Verbal feedback was given to students about their performance maximal power (result from the previous repetition) directly after their previous attempt by the examiner.

3. Verbal feedback was given to students about their performance maximal power (result from the previous repetition) directly after their previous attempt and verbal encouragement by the examiner ("faster - go") during their attempt.

For assessing the strength abilities parameters (determining maximal power) a monitoring device, namely FITROdyne (FiTRONiC, Bratislava, SVK) was used. This machine can measure the vertical speed and length of motion, particularly in strength exercises. This is due to a sensor which is stretched with an ox of dumbbells. On the basis of weight and 
acceleration, the system can calculate force, power and position (37).

$10 \mathrm{~m}$ and 30m Sprint Test. The main aim of this test is to determine acceleration and speed. Both days of measurement started with warming up which contained athletic running drills, dynamic stretching and one full sprint of 15 meters and then students sprinted two times $30 \mathrm{~m}$ distance with the task to run as fast as possible with the different stimuli. All students started from standing position with one foot forward and $1 \mathrm{~m}$ behind the start line. Participants were not provided a "go or start" command, they were running at their own discretion. All the runs were performed on the running track. The rest ratio between sprints was 1:15-1:20. Times on the 10 and $30 \mathrm{~m}$ distances were measured.

The selected stimuli were:

1. Students ran alone without any external stimuli.

2. Students ran alone with verbal encouragement from examiner ("faster - go - go - go") during the sprint.

3. Students made pairs (sprint with partner), when one of them was the hunter and the second the rabbit. The rabbit started about 3 meter in front of the hunter. the task of the hunter was to finish the $30 \mathrm{~m}$ distance before the rabbit. The race started on the acceleration of the hunter. After the race, both students changed their roles. The hunter's time was measured with verbal encouragement from an examiner during the sprint.

For assessing the speed of students, FITRO Gates photocell device (FITRONIC, Bratislava, SVK) was used for the distances 10 and $30 \mathrm{~m}$.

High jump with FiTRO JUMPER. The high jump test measures explosive strength of the lower body. Students underwent general warm up with jogging, squats and calf jumps and at the end performed four-practice attempts of high jump without supporting arm swing for each jump. Thereafter, participants were familiarized with the test procedures. The main test contained three high jumps with the hands placed on the hips and without bending their knees. Students began from an upright standing position. Participants were instructed to start the jump (on their own signal) with a downward movement, which was immediately followed by a concentric upward movement, resulting in a maximal vertical jump (38). All of the students performed all jumps barefoot. The height of the football ball was individually adjusted approximately $5 \mathrm{~cm}$ above the apex the head reached during familiarisation trials. The task was to jump as high as possible and stay on the mattress as short a time as possible. Quality of the jump technique was controlled through visual on-site inspection of the experimenter. The most powerful jump of the three was recorded. The rest between the sets of three jumps was 40-60s.

The selected stimuli were:

1. High jump without any external stimuli.

2. High jump with a verbal encouragement from examiner ("higher") during the attempt.

3. High jump with an aim to touch a ball (hanging above the student) with the forehead and with verbal encouragement from an examiner during the jump.

The power that was produced during jumps was measured with the FiTRO Jumper device (FITRONIC, Bratislava, SVK). The Jumper consists of a special contact switch mattress connected by a special interface to a computer (39). The system measures contact and flight times (with an accuracy of $1 \mathrm{~ms}$ ) during serial jumps and calculates basic biomechanical parameters. The reliability of the test has been proven to be sufficient enough (40) to be applied to functional diagnostics of athletes (41).

Data Analysis. Data analysis were performed by using the statistical program IBM SPSS Statistics 21 (IBM Corporation, Armonk, NY, USA). The mean and standard deviation (SD) were used for presenting results of measurements. The Kolmogorov Smirnov test for normality was used on all variables. Data showed a normal distribution. A repeated measures one-way Anova was employed with Bonferroni Post Hoc test for finding differences between physical fitness variables fitness tests with or without external stimuli. All data met the assumptions of withinsubjects ANOVA. The level of significance was set at $\mathrm{p} \leq 0.05$ and statistically significant differences were marked with a symbol (*).

\section{RESULTS}

The results from the Bench Press exercise show that NAS improved in mean power by about $21.3 \mathrm{~W}(5.15 \%, \mathrm{P}=0.021)$ in their second stimulus (feedback about their power performance) compared to the first stimulus (without stimulus). PAS did not improve statistically during the Bench Press measurements (Figure 1). 


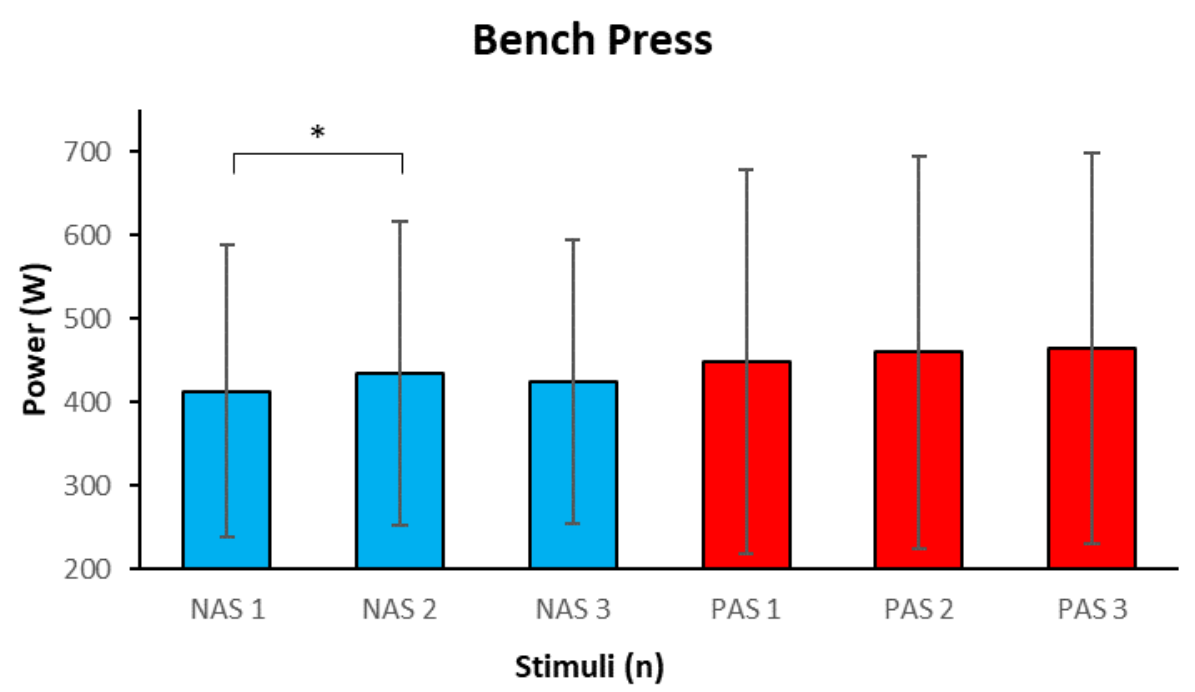

Figure 1. The Mean Power (W) Produced During Bench Press at Different Stimuli $\left({ }^{*} \mathbf{P} \leq 0.05\right)$.

\section{0m Sprint}

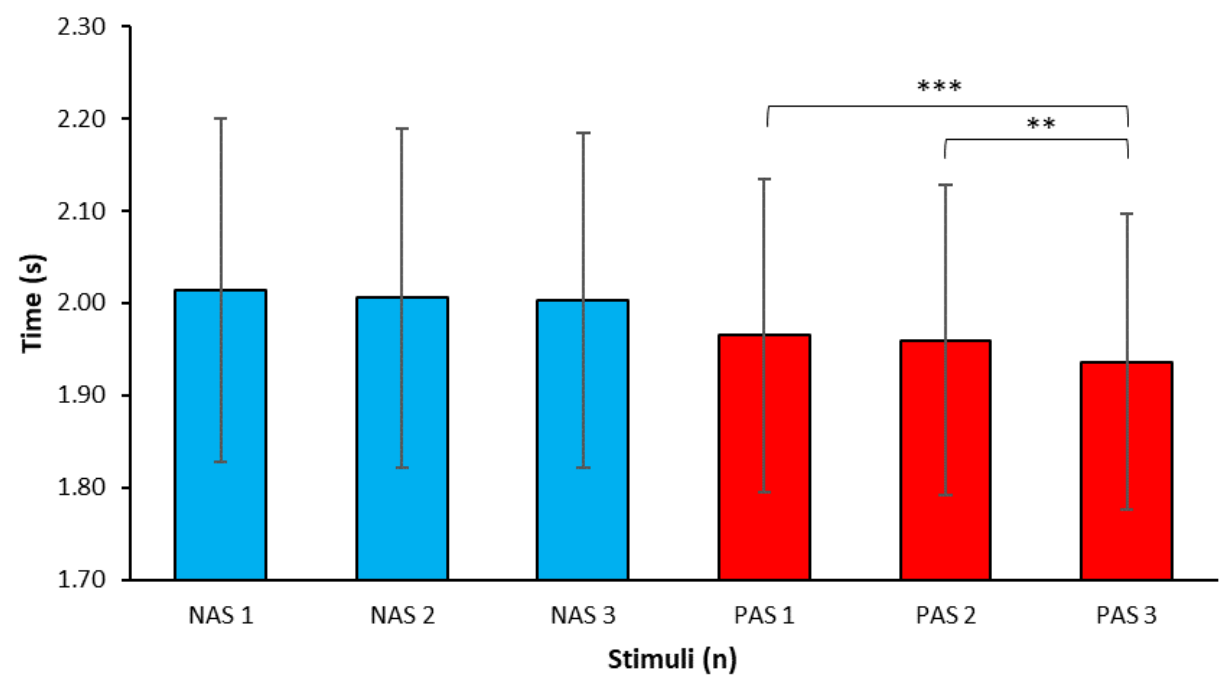

Figure 2. The Mean Time (s) Produced During 10m Sprint at Different Stimuli (**P $\leq 0.01, * * * P \leq 0.001)$.

In the $10 \mathrm{~m}$ sprint test the PAS decreased the mean time during the third stimulus (running in pairs + VE) compared to the first stimulus (without feedback) by about $0.029 \mathrm{~s}(1.5 \%, \mathrm{P}=$ 0.000 ) and the second stimulus (verbal encouragement) by about $0.024 \mathrm{~s}(1.24 \%, \mathrm{P}=$ 0.001). NAS showed no change statistically during the $10 \mathrm{~m}$ sprint measurements (Figure 2).
The 30m sprint test showed similar results (Figure 3 ) as the $10 \mathrm{~m}$ sprint when the NAS and PAS decreased the time in the third stimulus compared to the second stimulus by about $0.053 \mathrm{~s}(1.06 \%, \mathrm{P}$ $=0.006)$ and $0,089 \mathrm{~s}(1.86 \%, \mathrm{P}=0.000)$. Moreover, PAS also decreased the time in the third stimulus compared to the first by about $0.079 \mathrm{~s}(1.65 \%, \mathrm{P}=0.006)$. 


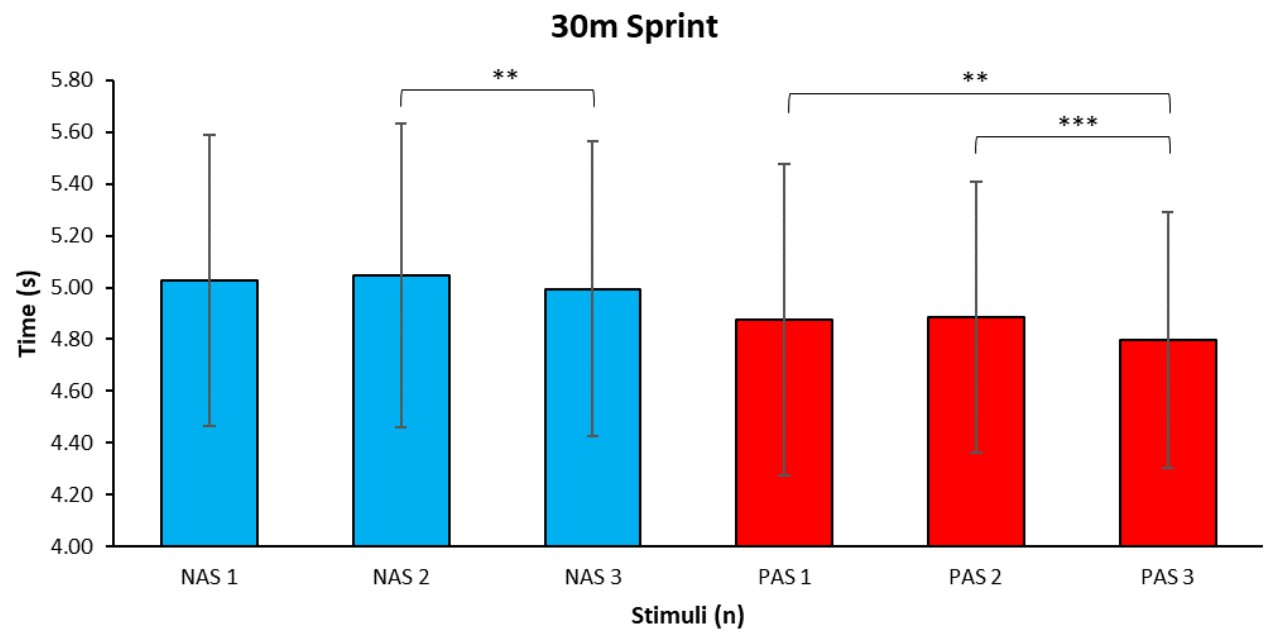

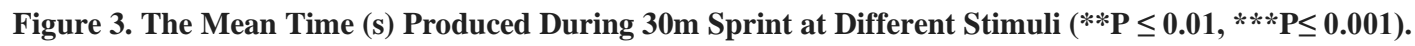

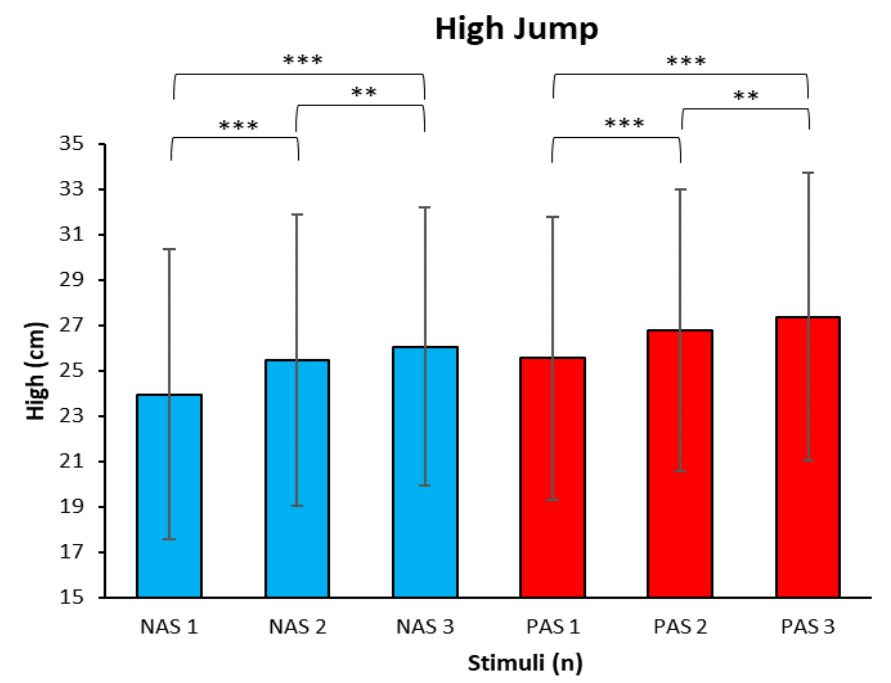

Figure 4. The Mean High (cm) Produced During High Jump at Different Stimuli $(* * P \leq 0.01, * * * P \leq 0.001)$.

The high jump test (Figure 4) recorded significant differences in height $(\mathrm{cm})$ between all stimuli in each group of students (NAS, PAS). The third stimulus (reach the subject + VE) was the most effective compared to the second stimulus (VE) and first stimulus (no feedback). Students (NAS, PAS) improved after the second stimulus compared to the first stimulus by about $1.53 \mathrm{~cm}(6.39 \%, \mathrm{P}=0.000)$ and $1.24 \mathrm{~cm}(4.85 \%, P=0.000)$. Improvements were also recorded after the third compared to the first stimulus by about $2.11 \mathrm{~cm}(8.81 \%, \mathrm{P}=$ $0.000)$ and $1.83 \mathrm{~cm}(7.16 \%, \quad \mathrm{P}=0.000)$ respectively. The next enhanced performance was seen comparing the third compared to the second stimulus $(0.58 \mathrm{~cm}, 2.28 \%, \mathrm{P}=0.013$ and $0.59 \mathrm{~cm}, 2.2 \%, \mathrm{P}=0.002)$.

\section{DISCUSSION}

The study results support the hypothesis that external stimuli have a greater impact on the results from fitness tests than without external stimuli in all selected tests and in both groups (NAS, PAS). Both of the groups improved significantly after receiving external stimuli in High Jump. The PAS also improved in 10 and $30 \mathrm{~m}$ sprint tests, but in the bench press test a significant change was recorded only in the nonactive group. This could have happened because of the limited experience of students executing 
this kind of exercise with external load (barbell, weights), so the stimuli was not strong enough to improve their motivation and therefore performance. The other fitness tests in this study were closer to basic movements like running and jumping, so for this reason the external stimuli could better enhance their performance. No positive significance difference was recorded in the execution of the selected fitness tests without external stimuli. A combination of external stimuli led to greater statistical significant changes than if just one external stimulus were used. This hypothesis was confirmed in the high jump and the 10 and $30 \mathrm{~m}$ sprint tests in PAS. On the other hand, in the exercise bench press and $10 \mathrm{~m}$ sprint students NAS improved significantly more after just one external stimulus (performance feedback respective verbal encouragement).

In similar studies $(24,42)$ minimal differences in strength testing were recorded after applying verbal encouragement, but those worked mostly with athletes. They assumed that maximal strength performance might not be sensitive enough to external verbal stimulation. Silva (43), found out that the verbal and visual stimuli alone were more effective in controlling the coactivation of the muscles during isometric contraction extension without changing the muscle strength. On the other hand, Lee (30) found that beginner athletes show greater changes in strength (4.7\%). This corresponds to the results of NAS in this study.

Findings from the 10 and $30 \mathrm{~m}$ sprint tests show that combination of external stimuli lead to greater improvement of performance than verbal encouragement or performance without stimuli which shows its importance for students' competitive environment. Verheijen (32) noticed differences for three age groups (U15, U17, U19) of football players performing $10 \mathrm{~m}$ sprint test in non-competitive (1 player), competitive conditions ( 2 players) and in specific football competitive situation (with ball). The second group improved compared to first group by about $2.5 \%$. The third group showed even more difference: $(6.5 \%)$ compared to first group. Also in another study (44) undergraduate college students doing a $20 \mathrm{~m}$ sprint achieved significantly better results than the control group (3.2\%). Edwards (45) in his study used verbal feedback in sprint $(2 \times 30 \mathrm{~s}$ Wingate $)$ cycling tasks on untrained, recreationally active participants and found a statistically significant difference between groups with and without VE. This does not correspond with our results, which may indicate that verbal encouragement does not have any significant positive effect on the student's performance in both groups. On the other hand, the great statistically significant change was achieved for 10 and $30 \mathrm{~m}$ sprints in PAS and the $30 \mathrm{~m}$ sprint of NAS after applying verbal + goal-oriented stimuli. This could have happened because of the realistic execution of this exercise having a clear achievable aim.

In the high jump test the biggest statistical significant differences between stimuli were seen. The results show significant improvement of students (NAS and PAS) after applying external stimuli compared to without stimuli. The significant changes were even between the verbal encouragement and goal-oriented stimulus together with verbal encouragement. This visible and achievable aim (ball) could have maximized the potential of students to achieve maximal performance and motivation. Vasconcelos (46) applied VE during vertical jump test on U17 futsal athletes. The main findings was that players improved in squat jump about $9.2 \%$ and in countermovement jump about $4.8 \%$. Also in the study (47) where recreationally trained male subjects were focusing on the target further from their body during standing long jump achieved significantly better results than group without stimuli. This is a very similar result to our study. Keller (48), found out that augmented feedback (the jump height was visually displayed directly after landing) was even more effective than the high jump with an aim touching a ball together with VE about $2.6 \%$.

The main finding of this study was that the presence of external stimuli or a combination thereof lead to increasing performance compared to execution without external stimuli during selected fitness tests in both groups. It has to be mentioned that short duration, explosive and intensive exercises have smaller chance and space (ceiling effect) for improvement and positive responses compare to endurance exercises. Applying selected external stimuli shows greater results and we can confirm that both groups positively react to external stimuli during the high jump and $30 \mathrm{~m}$ sprint. NAS group statistically reacted better on one stimulus (performance feedback respective VE) in Bench Press and 30m sprint when PAS saw significantly better results 
after applying combination of external stimuli. It is just questionable which and how many of them would be still beneficial for improving performance. This difference between the groups needs deeper investigation in future studies.

Testing explosive strength and speed abilities under simulated condition with external stimuli could represent a new approach in functional diagnostic measurement of PAS or NAS in physical education and sports. Although there are many different kinds of variation of fitness tests, most of them do not involve reactions to external stimuli as the motivation factor, which can influence the final performance. Therefore, testing and training conditions should contain these stimuli for appropriate assessment of fitness abilities, but could also be used during a variety of exercises in physical education classes. Challenging, competitive and motivation environment during testing or exercising may also help to increase motivation, focus, effort and enjoyment during different exercise and tasks (49).

The main limitation of the study was that students always started testing without external stimuli and for better interpretations of results all testing should be done in a counterbalancing manner. Secondly, some factors could have influenced the results of the study like the outdoor environment during the testing, mental fatigue from previous classes and the number of sleep hours. Standard operating procedures for verbal encouragement were set up based on the words but not up to the frequency or number of repetitions. This should be unified during testing.

In future studies, it would be interesting to separate goal-oriented stimulus from verbal encouragement, which would show the effect of this stimulus and not its combination. Furthermore, applying these external stimuli to specific skills tests in different sport situations could examine the effect of combining three or more stimuli on athletes or compare the effect of different external stimuli on performance.

\section{CONCLUSION}

These findings demonstrate the positive effect of using selected external stimuli compared to not using these external stimuli on the physical fitness of non-physically and physically active male students during fitness testing. However, one stimulus (performance feedback, verbal encouragement) had a bigger impact on NAS and the combination of external stimuli a bigger effect on PAS. Specific, challenging, competitive environments could positively change results in fitness tests. Goal-oriented stimuli, which are set up in a realistic, challenging and enjoyable scenario are appreciated by students and lead to greater motivation during physical activity. Verbal encouragement or performance feedback are effective in particular situations, and also only with particular students. Thus, it is very important for the teacher to recognize in which scenario and on which students he will use this kind of stimulus. The external stimuli mentioned in this study could be used during testing or exercise for better motivation, increased performance and activation for specific task PAS and NAS, and could be also a useful tool for teachers during physical education classes.

\section{APPLICABLE REMARKS}

- The findings reported in this study suggest the use of selected external stimuli during fitness testing for a more objective measurement of student performance and thus their motivation.

- The practitioner should build an environment in which subjects will be able to achieve their maximal performance.

- For NAS it is advisable to use verbal encouragement or performance feedback, and for PAS, a combination of external stimuli for selected fitness tests of explosive strength and speed abilities.

\section{ACKNOWLEDGMENTS}

I would like to thank you KFUPM University, specifically the Deanship of Scientific Research and the Department of Physical Education for the opportunity to realize this project under a number (SB181037) and also my colleague Prof. Erika Zemkova for her effort, time and valuable information which she has provided during this project.

\section{FUNDING}

This research was funded by King Fahd University of Petroleum and Minerals, grant number: SB181037

\section{CONFLICT OF INTEREST}

The author declared no potential conflicts of interest with respect to the research, authorship, and/or publication of this article.

\section{DECLARATION}

The project was approved by the ethics committee of the Deanship of Scientific Research, King Fahd University of Petroleum and Minerals in Dhahran (SB181037). 


\section{REFRENCES}

1. Elliot AJ, Covington MV. Approach and avoidance motivation. Educat Psychol Rev. 2001;13(2):73-92. doi: 10.1023/A:1009009018235

2. Egli T, Bland HW, Melton BF, Czech DR. Influence of age, sex, and race on college students' exercise motivation of physical activity. $J$ Am Coll Health. 2011;59(5):399-406. doi: 10.1080/07448481.2010.513074 pmid: 21500059

3. Bekiari A. Verbal aggressiveness and leadership style of sports instructors and their relationship with athletes' intrisic motivation. Creative Educat. 2014;5(2):114. doi: 10.4236/ce.2014.52018

4. Kondric M, Sindik J, Furjan-Mandic G, Schiefler B. Participation motivation and student's physical activity among sport students in three countries. J Sport Sci Med. 2013;12(1):10.

5. Goudas M, Biddle S, Fox K. Achievement goal orientations and intrinsic motivation in physical fitness testing with children. Pediatr Exercise Sci. 1994;6(2):159-167. doi: 10.1123/pes.6.2.159

6. Wiersma LD, Sherman CP. The responsible use of youth fitness testing to enhance student motivation, enjoyment, and performance. Measure Physic Educat Exercise Sci. 2008;12(3):167-183. doi: 10.1080/10913670802216148

7. Karaba-Jakovljevic D, Popadic-Gacesa J, Grujic N, Barak O, Drapsin M. Motivation and motoric tests in sports. Med Pregl. 2007;60(5-6):231-236. doi: 10.2298/mpns0706231k pmid: 17988054

8. Bam A. Psychological Aspects of Physical Education [Internet]. 2016. Available from: https://www.slideshare.net/BamAmintao/psychological-aspects-of-physical-education-65717489.

9. Winnick J, Porretta DL. Adapted physical education and sport. Human Kinetic. 2016.

10. Schroeder SL, Lomenick AF, Herdman BK, Tompkins BK, Sutherland EC. Effects of External Stimuli on Exercise Enjoyment in College Females. Int J Exercise Sci Conference Proceed. 2016;11(4):46.

11. Argus CK, Gill ND, Keogh JW, Hopkins WG. Acute effects of verbal feedback on upper-body performance in elite athletes. $J$ Strength Cond Res. 2011;25(12):3282-3287. doi: 10.1519/JSC.0b013e3182133b8c pmid: 22076083

12. Nicaise V, Cogérino G, Bois J, Amorose AJ. Students' perceptions of teacher feedback and physical competence in physical education classes: Gender effects. J Teach Physic Educat. 2006;25(1):36-57. doi: $10.1123 /$ jtpe.25.1.36

13. Reinboth M, Duda JL, Ntoumanis N. Dimensions of coaching behavior, need satisfaction, and the psychological and physical welfare of young athletes. Motivat Emotion. 2004;28(3):297-313. doi: 10.1023/B:MOEM.0000040156.81924.b8

14.Badami R, VaezMousavi M, Wulf G, Namazizadeh M. Feedback after good versus poor trials affects intrinsic motivation. Res $Q$ Exerc Sport. 2011;82(2):360-364. doi: 10.1080/02701367.2011.10599765 pmid: 21699117

15. Smither JW, London M, Reilly RR. Does performance improve following multisource feedback? A theoretical model, meta-analysis, and review of empirical findings. Person Psychol. 2005;58(1):33-66. doi: 10.1111/j.1744-6570.2005.514_1.x

16. Halperin I, Pyne DB, Martin DT. Threats to internal validity in exercise science: a review of overlooked confounding variables. Int J Sports Physiol Perform. 2015;10(7):823-829. doi: 10.1123/ijspp.2014-0566 pmid: 25756869

17. Coker CA. Motor learning and control for practitioners. Routledge2017.

18. Strube G, Strand B. Can Feedback Affect Motivation? J Oklahoma Associat Health Physic Educat Recreat Dance. 2015;52(2).

19. Koka A, Hein V. Perceptions of teacher's feedback and learning environment as predictors of intrinsic motivation in physical education. Psychol Sport Exercise. 2003;4(4):333-346. doi: 10.1016/S14690292(02)00012-2

20.Guéguen N, Martin A, Andrea CR. "I am sure you'll succeed": When a teacher's verbal encouragement of success increases children's academic performance. Learn Motivat. 2015;52:54-59. doi: 10.1016/j.lmot.2015.09.004

21. American Thoracic S, American College of Chest P. ATS/ACCP Statement on cardiopulmonary exercise testing. Am J Respir Crit Care Med. 2003;167(2):211-277. doi: 10.1164/rccm.167.2.211 pmid: 12524257 
22.Laboratories ATSCoPSfCPF. ATS statement: guidelines for the six-minute walk test. Am J Respir Crit Care Med. 2002;166(1):111-117. doi: 10.1164/ajrccm.166.1.at1102 pmid: 12091180

23.Ferguson B. ACSM's guidelines for exercise testing and prescription 9th Ed. 2014. J Canadian Chiropractic Associat. 2014;58(3):328.

24. Selmi O, Khalifa WB, Ouerghi N, Amara F, Zouaoui M. Effect of Verbal Coach Encouragement on Small Sided Games Intensity and Perceived Enjoyment in Youth Soccer Players. J Athl Enhanc. 2017;6(3):16-17. doi: 10.4172/2324-9080.1000262

25. Midgley AW, Marchant DC, Levy AR. A call to action towards an evidence-based approach to using verbal encouragement during maximal exercise testing. Clin Physiol Funct Imaging. 2018;38(4):547553. doi: 10.1111/cpf.12454 pmid: 28737294

26. Neto JM, Silva FB, De Oliveira AL, Couto NL, Dantas EH, de Luca Nascimento MA. Effects of verbal encouragement on performance of the multistage $20 \mathrm{~m}$ shuttle run. . Acta Sci Health Sci. 2015;37(1):2530. doi: 10.4025/actascihealthsci.v37i1.23262

27. Malik H, Flowers K. Augmenting Performance: Vocal Activity Compared to Presence in the Social Facilitation of Running. J Stud Res. 2020;9(1). doi: 10.47611/jsrhs.v9i1.1160

28. Anzak A, Tan H, Pogosyan A, Brown P. Doing better than your best: loud auditory stimulation yields improvements in maximal voluntary force. Exp Brain Res. 2011;208(2):237-243. doi: 10.1007/s00221010-2474-1 pmid: 21063690

29. Belkhiria C, de Marco G, Driss T. Effects of verbal encouragement on force and electromyographic activations during exercise.2018.

30.Lee H, Shin J, Kim D, Park J. Effect of verbal encouragement on quadriceps and knee joint function during three sets of knee extension exercise. Isokinetic Exercise Sci. 2020:1-7. doi: 10.3233/IES-203203

31.McNair PJ, Depledge J, Brettkelly M, Stanley SN. Verbal encouragement: effects on maximum effort voluntary muscle action. Br J Sports Med. 1996;30(3):243-245. doi: 10.1136/bjsm.30.3.243 pmid: 8889120

32. Verheijen R. The Original Guide to Football Periodisation: Always Play with Your Strongest Team, Part 1. World Football Academy2016.

33.Zemkova E, Vilman T, Kovacikova Z, Hamar D. Reaction time in the agility test under simulated competitive and noncompetitive conditions. J Strength Cond Res. 2013;27(12):3445-3449. doi: 10.1519/JSC.0b013e3182903222 pmid: 23524364

34.Bullinger D. Effect of competition on performance and physiological responses. 2013. doi: 10.1249/01.mss.0000493340.12996.aa

35. Kraemer WJ, Ratamess NA, Fry AC, French DN. Strength Training: Development 22 and Evaluation of Methodology. Physiologic Assessment Human Fitness. 2006;23:24.

36. Adam C, Klissouras V, Ravazzolo M, Renson R, Tuxworth W, Kemper HC, et al. EUROFIT-European test of physical fitness.

37. Author. 2020.

38.Lesinski M, Muehlbauer T, Granacher U. Concurrent validity of the Gyko inertial sensor system for the assessment of vertical jump height in female sub-elite youth soccer players. BMC Sports Sci Med Rehabil. 2016;8:35. doi: 10.1186/s13102-016-0061-x pmid: 27895923

39. Hamar D, Tschan H. Výskokový ergometer-princíp a možnosti uplatnenia v diagnostike trénovanosti a tréningovej praxi. Príspevok z pracovného seminára Diagnostika a rozvoj odrazových schopností. 1991.

40. Tkac M, Hamar D, Komadel L, Kuthanova O. Measurement of anaerobic power of the lower limbs by a method of repeated vertical jumps. Res Sport Med Int J. 1990;1(4):317-325. doi: $10.1080 / 15438629009511890$

41.Zemková E, Hamar D. JUMP ERGOMETER IN SPORT PERFORMANCE TESTING. Acta Universitatis Palackianae Olomucensis. Gymnica. 2005;35(1).

42. Obmiñski Z, Mroczkowska H. Verbal encouragement does not improve maximal isometric hand grip strength in male judokas. A short report. J Combat Sport Martial Art. 2015;6:63-66. doi: $10.5604 / 20815735.1195355$

43. Silva SB, de Abreu LC, Valenti VE, Nogueira DV, Moraes ER, Natividade V, et al. Verbal and visual stimulation effects on rectus femoris and biceps femoris muscles during isometric and concentric. Int Arch Med. 2013;6(1):38. doi: 10.1186/1755-7682-6-38 pmid: 24099489 
44.Porter JM, Wu WF, Crossley RM, Knopp SW, Campbell OC. Adopting an external focus of attention improves sprinting performance in low-skilled sprinters. J Strength Cond Res. 2015;29(4):947-953. doi: 10.1097/JSC.0000000000000229 pmid: 25811269

45.Edwards AM, Dutton-Challis L, Cottrell D, Guy JH, Hettinga FJ. Impact of active and passive social facilitation on self-paced endurance and sprint exercise: encouragement augments performance and motivation to exercise. BMJ Open Sport Exerc Med. 2018;4(1):e000368. doi: 10.1136/bmjsem-2018000368 pmid: 30109119

46. Vasconcelos AB, Farinon RL, Perasol DM, dos Santos JM, de Freitas VH. Influência de estímulos motivacionais no desempenho em testes de salto vertical de atletas de futsal sub-17. Revista Brasileira de Educação Física e Esporte. 2020;34(4):727-733. doi: 10.11606/issn.1981-4690.v34i4p727-733

47.Porter JM, Anton PM, Wu WF. Increasing the distance of an external focus of attention enhances standing long jump performance. $J$ Strength Cond Res. 2012;26(9):2389-2393. doi: 10.1519/JSC.0b013e31823f275c pmid: 22067252

48. Keller M, Lauber B, Gottschalk M, Taube W. Enhanced jump performance when providing augmented feedback compared to an external or internal focus of attention. J Sports Sci. 2015;33(10):1067-1075. doi: 10.1080/02640414.2014.984241 pmid: 25529245

49.Ekkekakis P, Parfitt G, Petruzzello SJ. The pleasure and displeasure people feel when they exercise at different intensities: decennial update and progress towards a tripartite rationale for exercise intensity prescription. Sports Med. 2011;41(8):641-671. doi: 10.2165/11590680-000000000-00000 pmid: 21780850 